\title{
Reduced Levels of Acetylcholine Receptor Expression in Chick Ciliary Ganglion Neurons Developing in the Absence of Innervation
}

\author{
Lynn S. Arenella, ${ }^{a}$ Jeanne M. Oliva, and Michele H. Jacob \\ Worcester Foundation for Experimental Biology, Shrewsbury, Massachusetts 01545
}

Chick ciliary ganglion neurons receive innervation from a single source, the accessory oculomotor nucleus (AON), and nicotinic ACh receptors (AChRs) mediate chemical synaptic transmission through the ganglion. Previous experiments examining the developmental expression of AChRs in embryonic chick ciliary ganglion neurons in situ have shown that AChR levels increase substantially in the neurons at the time of innervation. Prior to synapse formation, few AChRs are detected in the neurons. In the present experiments, the role of presynaptic inputs in inducing an increase in AChRs was established by examining AChR levels in ciliary ganglion neurons that have been deprived of innervation by surgical ablation of the AON prior to synapse formation. AChR levels were dramatically reduced in neurons of input-deprived ganglia as compared to control innervated neurons at all developmental stages examined from embryonic day (ED) 5 to ED 12 as determined by indirect immunocytochemical labeling of frozen ganglion sections with the anti-AChR monoclonal antibody $\mathbf{m A b} 35$, and light microscopy. In contrast, neuronal somata of input-deprived and control ganglia had equivalent levels of immunolabeling for three other components, a transmembrane glycoprotein of synaptic vesicles, SV2, and two microtubule-associated proteins, MAP $1 B$ and MAP 2, from ED 5 up to ED 10. The results demonstrate that presynaptic inputs specifically increase the levels of AChR expression In developing neurons.

In addition, changes in the levels of immunolabeling for AChRs, SV2, MAP 1B, and MAP 2 in neuronal somata after ED 10 demonstrate that other major developmental events also influence the levels of these components in neurons. Declines in the intensity of AChR, SV2, MAP 1B, and MAP 2 immunolabeling within a subset of neuronal somata in both operated and control ganglia at ED 10 and 12 coincide with the period of neuronal cell death. Increases in AChR labeling

Received Nov. 11, 1992; revised Apr. 26, 1993; accepted May 3, 1993.

We thank Bill Richardson for his assistance with the chick embryo surgeries required for this study, and Deborah Lawson for her assistance in preparing the figures. We also thank Dr. Darwin Berg (University of California at San Diego) for generously providing the hybridoma cell line producing the monoclonal antibody mAb 35, which was originally isolated by Dr. Jon Lindstrom and colleagues (University of Pennsylvania); Dr. Kathleen Buckley (Harvard Medical School) and Dr. Regis Kelly (University of California at San Francisco) for kindly providing the anti-SV2 monoclonal antibody; and Dr. Richard Vallee (Worcester Foundation for Experimental Biology) for providing the MAP IB-2 and MAP 2 monoclonal antibodies. Grant support was provided by the National Institutes of Health (NS 21725) and the Pfeiffer Foundation.

Correspondence should be addressed to Michele H. Jacob, Worcester Foundation for Experimental Biology, 222 Maple Avenue, Shrewsbury, MA 01545.

Present address: Department of Natural Sciences, Bentley College, 175 Forest Street, Waltham, MA 02154.

Copyright (C) 1993 Society for Neuroscience $0270-6474 / 93 / 134525-13 \$ 05.00 / 0$ in the rest of the neuronal population of input-deprived ganglia at ED 12 suggest that, in addition to innervation, synapse formation with the peripheral target tissue influences AChR levels in developing neurons in situ.

[Key words: ACh receptors, developing neurons, nicotinic cholinergic transmission, parasympathetic ganglion, innervation, induction, receptor expression, immunocytochemistryl

Nicotinic $A C h$ receptor (AChR) levels and properties are developmentally regulated in both nicotinic cholinergic neurons and skeletal muscle. In muscle, signals from the presynaptic motoneuron influence $\mathrm{AChR}$ gene transcription and the number, subunit composition, functional properties, metabolic stability, and distribution of AChRs (Fambrough, 1979; Salpeter, 1987; Schuetze and Role, 1987; Brehm and Henderson, 1988; Changeux, 1991). In neurons, the role of innervation in regulating AChR expression has been less clearly established, particularly during the developmental stages of synapse formation. In addition, the regulation of $\mathrm{AChR}$ expression may be more complex in neurons than in muscle since neurons establish connections with presynaptic inputs and peripheral target tissues, potentially exposing the cells to regulatory influences from multiple sources.

In mature neurons, signals from the presynaptic input regulate AChR channel kinetics and the maintenance of AChR protein and $\alpha 3$ subunit mRNA levels (Marshall, 1985; Jacob and Berg, 1987, 1988; Boyd et al., 1988). Recent studies of developing chick parasympathetic ciliary ganglion neurons in situ suggest that innervation induces an increase in AChR expression. Normally, two populations of AChRs exist in embryonic chick ciliary ganglion neurons. The internal pool of AChRs, which represents approximately two-thirds of the total number of receptors, is associated with organelles that function in the biosynthesis, processing, and transport of integral plasma membrane proteins, specifically, the rough endoplasmic reticulum, portions of the nuclear envelope, Golgi complexes, coated pits, coated vesicles, smooth-membraned vacuoles, and multivesicular bodies (Jacob et al., 1986; Stollberg and Berg, 1987; Jacob, 1991). Interestingly, only $5 \%$ of the internal pool of AChRs is destined for the cell surface (Stollberg and Berg, 1987). On the neuronal surface, AChRs are predominantly localized in the specialized postsynaptic membrane (Jacob et al., 1984, 1986; Loring and Zigmond, 1987; Jacob, 1991). At stages prior to innervation [embryonic day (ED) 3.5-4], few AChRs are present in intracellular pools and no AChRs can be detected on the surface of the neurons (Jacob, 1991). During the period of synaptogenesis, substantial numbers of AChRs appear in both surface and internal pools. To determine whether innervation induces an increase in $\mathrm{AChR}$ expression, or whether the increase is solely the result of an 
intrinsic developmental program or other cell-cell interactions, we have examined AChR levels in chick ciliary ganglion neurons developing in situ in the absence of presynaptic input.

The chick parasympathetic ciliary ganglion is an ideal preparation for these investigations. It contains two populations of neurons, ciliary and choroid cells, both of which receive nicotinic cholinergic transmission from a single source, the accessory oculomotor nucleus (AON), and the AON is accessible for surgical removal in the embryo prior to the time of synapse formation in the ganglion (Martin and Pilar, 1963a,b; Cowan and Wenger, 1968; Narayanan and Narayanan, 1976; Landmesser and Pilar, 1978; Furber et al., 1987). Normally, innervation begins at ED 4.5 in the chick ciliary ganglion as determined by using light microscopy after immunocytochemical labeling with anti-SV2, a monoclonal antibody (mAb) to a transmembrane glycoprotein that is present in synaptic vesicles, and by using ultrastructural analysis (Jacob, 1991). By ED 8, functional chemical synapses are present on every neuron (Landmesser and Pilar, 1972). Further, the establishment of preganglionic synaptic connections precedes the time of target tissue innervation. At ED 8.5 the ciliary neurons begin to innervate the striated muscles of the iris and ciliary body, and at ED 10 the choroid neurons begin to innervate the smooth muscles in blood vessels of the choroid coat (Meriney and Pilar, 1987; Pilar et al., 1987). Peripheral synapse formation continues up to ED 14, and coincides with the period of naturally occurring cell death in the ganglion (Landmesser and Pilar, 1974). Hence, the role of presynaptic inputs in regulating $\mathrm{AChR}$ expression can be investigated separately from the consequences of these other developmental events by focusing on the earlier stages.

The dorsal mesencephalic region that gives rise to the AON can be surgically ablated at ED 4 without interfering with the migration of the neural crest progenitor cells of the ciliary ganglion from the region (Furber et al., 1987). Preganglionic tissuedeprived ciliary ganglion neurons were demonstrated to be healthy and to have established normal interactions with the target tissue in the eye up to ED 9 (Furber et al., 1987). Specifically, the ultrastructural appearance, mean nuclear diameter, and number of neurons in the ganglion, as well as the number of axons and the establishment of axonal contact with the target tissue, all appear to be unaffected by the operation. From ED 9 on, however, there is an increased cell loss, with only $10-15 \%$, as opposed to $50 \%$, of the neurons remaining after the normal cell death period.

Consequently, to establish the role of presynaptic signals in the induction of AChR expression in developing neurons, the AON was surgically ablated on ED $3.5-4$, which precedes the time of synapse formation in the ganglion, and AChR levels were compared in ED 8 input-deprived and control ciliary ganglion neurons by using indirect immunocytochemical labeling and light microscopy. We focused on ED 8 because this is the stage at which the largest differences in AChR levels between neurons of input-deprived and control ganglia (that could be attributed solely to the absence of presynaptic inputs) are expected to have developed. In addition, to test the possibility that an alteration in $\mathrm{AChR}$ expression in input-deprived ciliary ganglion neurons is merely the result of a general effect on neuronal health, the relative levels of three other neuronal proteins, the synaptic vesicle protein, SV2, and two microtubule-associated proteins, MAP 1B and MAP 2, were compared in neurons of operated and control ganglia. Specific changes in AChR levels over time in neurons developing in the absence of innervation were also examined by investigating AChR, SV2, MAP 1B, and MAP 2 levels in ganglia from operated and control embryos ranging from ED 5 to $E D 12$. We report here that, at all stages examined, AChR levels are dramatically reduced in chick ciliary ganglion neurons developing in situ in the absence of presynaptic input. In contrast, the relative amounts of three other neuronal components do not appear to differ in neurons of input-deprived and control ganglia, at least until ED 10.

\section{Materials and Methods}

\section{Embryos and staging}

White Leghorn embryonated chick eggs (Spafas, Norwich, CT) were maintained at $37^{\circ} \mathrm{C}$ in a forced-draft turning incubator until use. Embryos were staged according to the Hamburger and Hamilton (1951) classification scheme in order to ensure that the surgical manipulation was performed at the appropriate developmental time.

\section{Embryonic surgery}

Using a previously described surgical approach (Furber et al., 1987), the AON was ablated in embryos at ED 3.5-4 (stages 21-23), which precedes the time of synapse formation in the ciliary ganglion (Jacob, 1991). In early developing chick embryos, the AON is quite accessible since the nucleus lies bilaterally near the surface along the midline region of the dorsal mesencephalon. For the surgery, a small hole was made in the blunt end of the egg shell. Using a dissecting microscope with fiber optic illumination and a fine forceps, a little flap of the amnion was pulled away to reveal the head of the embryo. Using the forceps to hold the dorsal mesencephalic region in this opening, a small batteryoperated electrocautery (Storz Instruments, St. Louis, MO), whose tip had been sharpened to a fine point, was used to cauterize (for $2-4 \mathrm{sec}$ ) the entire middorsal mesencephalic region containing the AON. After cauterization, the head of the embryo was recovered with the flap of amniotic membrane and the opening in the egg shell was sealed with a coverslip and melted wax. The egg was replaced in a nonturning incubator at $37^{\circ} \mathrm{C}$ and allowed to continue development until the desired age was reached. Survival rates varied from $40 \%$ to $80 \%$. In addition, sham operations were always performed on other ED 3.5-4 embryos. Sham operations involved the same procedures used for the lesioned embryos with the exception of the cauterization step.

\section{Paraffin histology}

Paraffin histological examination was used to inspect the region of the mesencephalon containing the AON in operated and control embryos at various stages of development from ED 4 (stage 23) to ED 11 (stage 37). The entire head and eyes, including the ciliary ganglia, were fixed by immersion in either 4\% paraformaldehyde in PBS or $2 \%$ paraformaldehyde, $2 \%$ glutaraldehyde in PBS. Following processing for paraffin histology, including buffer rinses, dehydration, and embedding in either paraffin (Fischer Tissue Prep) or Surgipath Tissue Embedding Medium (Grayslake, IL), tissue was sectioned at $8 \mu \mathrm{m}$ and stained with unheated formal-thionin (Donovick, 1974).

The histological appearance and development of both the midbrain region containing the $A O N$ and the ciliary ganglion were examined in normal developing, sham-operated, and operated embryos. In particular, this region of the mesencephalon was examined in operated embryos at ED 7-8 (stages 30-34) to establish the complete bilateral destruction of the AON following surgery at ED 3.5-4. To map the exact extent of the lesions (see Fig. 1), serial transverse sections through the entire brains of four randomly selected ED 7-8 operated embryos were traced using a projecting microscope.

\section{Immunocytochemistry}

AChR levels, as well as the levels of three other neuronal components, were examined in ciliary ganglion neurons of operated and control embryos by using indirect immunocytochemical labeling of frozen ganglion sections.

Antibodies. $\mathrm{mAb} 35$ is a rat $\mathrm{mAb}$ that was raised against Electrophorus electric organ AChRs (Tzartos et al., 1981) and cross-reacts with neuronal AChRs (Jacob et al., 1984, 1986; Smith et al., 1985, 1986; Halvorsen and Berg, 1987, 1990; Schoepfer et al., 1989). mAb 35 was purified as previously described (Smith et al., 1985) from the medium 
of a hybridoma cell line that was kindly provided by Dr. Darwin Berg (University of California at San Diego). mAb 35 was diluted 1:100 in PBS and used at $0.1 \mu \mathrm{m}$. Anti-SV2 is a mouse mAb to the synaptic vesicle transmembrane glycoprotein SV2 (Buckley and Kelly, 1985). The anti-SV $2 \mathrm{mAb}$ was generously provided by Dr. Kathleen Buckley (Harvard Medical School) and Dr. Regis Kelly (University of California at San Francisco) and was used at a 1:50 dilution in PBS. Anti-MAP $1 \mathrm{~B}-2$ is a mouse mAb to MAP $1 \mathrm{~B}$ that is highly concentrated in axonal processes and is present in the soma of developing neurons (Bloom et al., 1985; Schoenfeld et al., 1989). (The number " 2 " in the name refers to the order of isolation of this particular hybridoma clone.) Anti-MAP 2 is a mouse mAb to MAP 2 that is predominantly present in the dendrites and in the soma of developing neurons (Bernhardt and Matus, 1984; Burgoyne and Cumming, 1984; DeCamilli et al., 1984; Sims et al., 1988). Anti-MAP 2 does not cross-react with MAP $1 \mathrm{~B}$ (Bloom and Vallee, 1983). mAbs to MAP 1B-2 and MAP 2 were the generous gift of Dr. Richard Vallee (Worcester Foundation for Experimental Biology) and were both used at a 1:200 dilution in PBS.

Labeling procedures. Indirect immunocytochemical labeling was carried out as previously described, with a few modifications (Jacob et al., 1986; Jacob, 1991). Ciliary ganglia were dissected from normal, shamorerated, and lesioned embryos on ED 5, 6, 7, 8, 10, and 12 (stages 26, $28-29,30-31,34,36$, and 38). Only lesioned embryos with normal eye development as determined by gross inspection at the time of dissection were used. Ganglia were lightly fixed with $0.5 \%$ paraformaldehyde in PBS for $1 \mathrm{hr}$, rinsed in PBS containing $0.75 \%$ glycine (PBS-glycine), infused with $2.3 \mathrm{M}$ sucrose for 1-2 hr, embedded in optimum cutting temperature compound, frozen, and stored at $-20^{\circ} \mathrm{C}(1-8 \mathrm{~d})$. Frozen sections $\left(6\right.$ or $8 \mu \mathrm{m}$ thick) were cut with a cryostat at $-18^{\circ} \mathrm{C}$. The sections were mounted on poly-L-lysine-coated glass slides, air dried for $30 \mathrm{~min}$, and stored overnight at $4^{\circ} \mathrm{C}$. The next day the sections were rinsed in PBS-glycine, incubated with the primary $m \Lambda b$ for $1 \mathrm{hr}$, rinsed in PBSglycine, and incubated with a biotinylated rabbit anti-rat antibody (in the case of mAb 35; Vector Laboratories, Burlingame, $\mathrm{CA}$ ) or a biotinylated horse anti-mouse antibody (in the case of the anti-SV2, MAP 1B-2, and MAP 2 mAbs; Vector Laboratories) at $0.1 \mu \mathrm{M}$ in PBS for 1 $\mathrm{hr}$. The sections were then rinsed in PBS, and incubated for $40 \mathrm{~min}$ with an avidin-biotinylated horseradish peroxidase (HRP) complex (Vectastain Elite ABC Kit, Vector Laboratories) that was prepared in PBS according to the manufacturer's instructions. After the sections were again rinsed in PBS, they were postfixed with $1 \%$ glutaraldehyde in PBS for $10 \mathrm{~min}$, rinsed once in PBS and once in $0.05 \mathrm{M}$ Tris- $\mathrm{HCl}$ buffer ( $\mathrm{pH} 7.4$ ) containing $7.5 \%$ sucrose, and incubated with $0.05 \% 3,3^{\prime}-$ diaminobenzidine and $\mathrm{H}_{2} \mathrm{O}_{2}(0.0006 \%)$ in the latter Tris- $\mathrm{HCl}$ buffer for $30 \mathrm{~min}$ in the dark. All immunocytochemical staining procedures were carricd out at room temperature in humidified chambers. After final rinses in Tris- $\mathrm{HCl}$ buffer, the sections were partially dried, mounted in glycerol, and viewed by bright-field microscopy with a Zeiss Axioskop microscope.

Controls. To prevent any differences in the processing of ganglionic sections from operated and control embryos during the labeling procedures, each slide contained three or four serial sections from both input-deprived and control ganglia. To establish the specificity of the labeling, a few slides from each experiment were processed as described above except that $\mathrm{mAb} 35$ was replaced with nonimmune rat serum (Calbiochem Corporation, La Jolla, CA) at an equivalent concentration of immunoglobulin or with PBS. Similarly, anti-SV2, MAP 1B-2, and MAP 2 mAbs were replaced with nonimmune mouse serum (Vector Laboratories, Burlingame, CA) or with PBS.

\section{Analysis of AChR labeling}

Although it is not possible, in the strictest sense, to quantitate the amount of HRP reaction product in the neurons (see, e.g., Sternberger, 1979), a semiquantitative method was established for comparing the relative levels of AChR immunolabeling in ganglionic ncurons of normal, shamoperated, and lesioned embryos. Ganglia were assigned to one of four labeling categories based on the number of labeled neurons, the amount of HRP reaction product within individual neurons, and the relalive level of immunolabeling across the entire cross-sectional area of the ganglion. Ganglia were scored as being (1) "intensely labeled" if most ( $75 \%$ or more) of the neurons were intensely labeled with HRP reaction product, (2) "moderately labeled" if $10-60 \%$ of the neurons were moderately or intensely labeled with HRP reaction product, while the remaining neurons were only lightly labeled, (3) "lightly labeled" if practically all of the neurons were lightly labeled with at most $0-10 \%$ of the neurons being either moderately or intensely labeled with HRP reaction product, and (4) "not labeled" if the vast majority of neurons contained levels of HRP reaction product similar to the background amounts present in sections treated with nonimmune serum or PBS in place of $\mathrm{mAb} 35$. Finally, only those ganglia that could be evaluated through all the sections on at least two slides were included in the results.

\section{Results}

\section{Surgical ablation of the $A O N$}

Paraffin histological examination was used to establish that the sole source of presynaptic inputs to the ciliary ganglion, the AON, was completely ablated in operated embryos. In normal and sham-operated embryos at early developmental stages (ED 4-5), the AON could not be identified as a discrete nucleus in the brain, although nests of cells representing the oculomotor primordium were found bilaterally along the midline region of the mesencephalon in these embryos. At ED 7-8, neurons of the AON were found just below the surface along the midline region of the dorsal midbrain in normal and sham-operated embryos, and at ED 11, the entire oculomotor complex, including the dorsolateral, dorsomedial, and ventromedial somatic subnuclei, was particularly distinct (Fig. $1 A$ ). In all of the brains from embryos that had received surgery on ED 3.5-4 to remove the $A O N$, the midbrain was reduced in size in comparison to the midbrain of normal and sham-operated embryos as determined by gross inspection at the time of dissection. The extent of the midbrain lesions was determined in four randomly selected ED 7-8 operated embryos by tracing serial transverse paraffin sections through the brains (Fig. $1 B$ ). The region of the midbrain that would normally contain the cells of the oculomotor complex was either completely missing or, in one case, was decreased in size and contained no morphologically identifiable neurons.

All of the ciliary ganglia from operated ED 7-8 embryos appeared normal by paraffin histology: there were no discernible differences in the light microscopic appearance of the neurons between ED 7-8 normal, sham-operated, and lesioned embryos (see also Furber et al., 1987). In all of the input-deprived ganglia, however, the preganglionic nerve was either missing or present as an extremely thin, wispy process, confirming the success of the operation. Ciliary ganglia were never dissected from lesioned or control embryos that appeared in any way to be abnormal, as sometimes occurred, for example, in the case of eye development.

\section{$A C h R$ expression in control and input-deprived neurons on $E D 8$}

To determine whether innervation induces an increase in $\mathrm{AChR}$ levels, the intensity and pattern of $\mathrm{AChR}$ immunolabeling were compared in ciliary ganglion neurons of lesioned, sham-operated, and normal developing ED 8 embryos. At ED 8 and all other stages of development, no differences were observed in the immunoreactivity of ciliary ganglion neurons from agematched normal developing and sham-operated embryos in any of the immunocytochemical labeling experiments; hence, they are subsequently referred to as "control embryos." Neuronal somata in ganglionic sections from ED 8 control embryos were intensely labeled when examined by light microscopy following AChR immunolabeling with mAb 35, a biotinylated secondary antibody, and an avidin-biotinylated HRP complex, and reaction for peroxidase activity (Fig. $2 A$ ). In contrast, neuronal nuclei and axons were not stained above background levels. The intense labeling of the neuronal somata represents the specific 

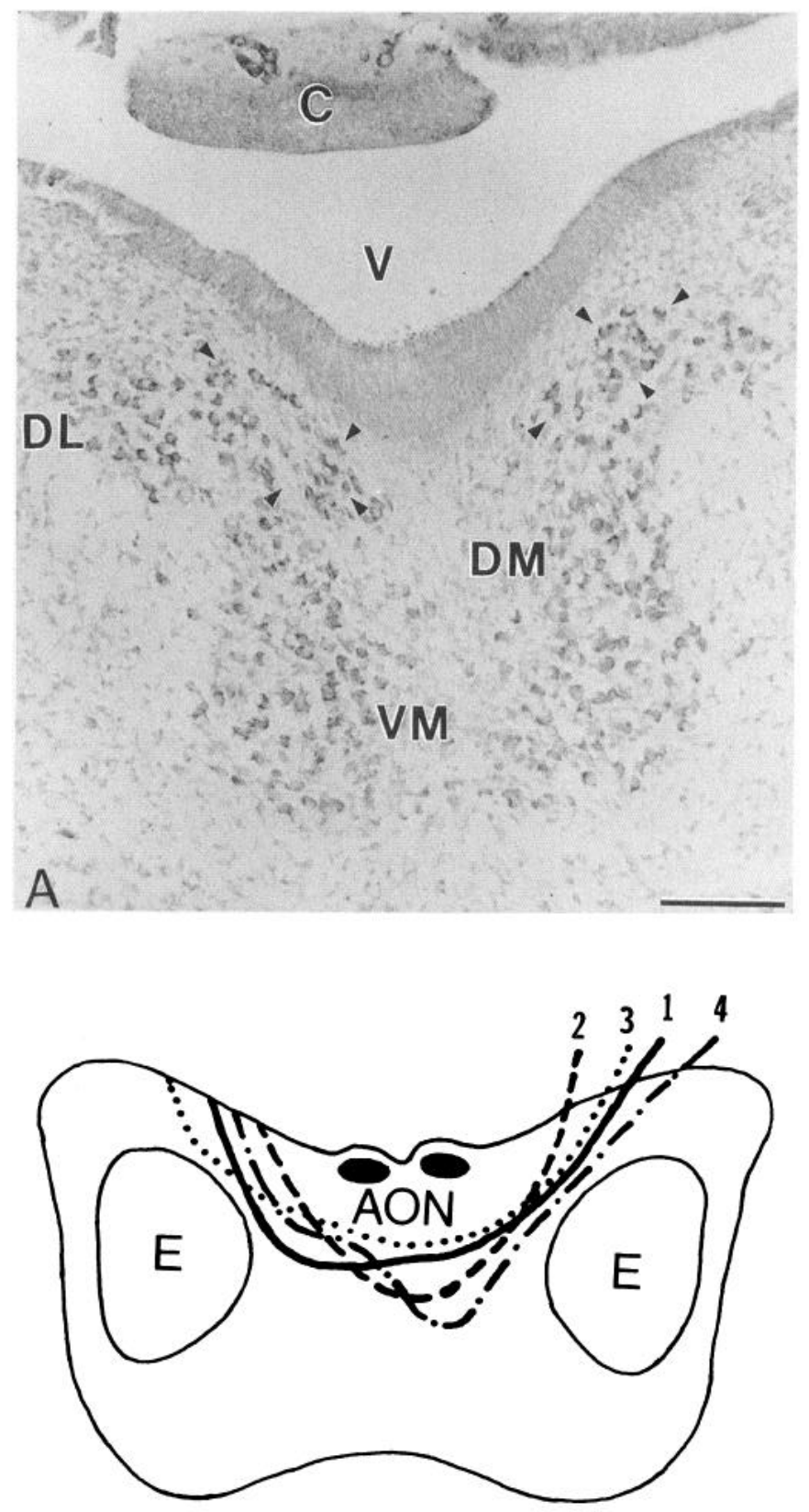

B

Figure 1. Transverse sections through the brain of control and operated chick embryos at the level of the oculomotor complex. $A$, Paraffin section of the midbrain in a normal developing ED 11 chick, demonstrating the location of the AON (small arrowheads). The AON comprises a distinct subnuclear group of the oculomotor complex that lies close to the surface along the midline region of the dorsal mesencephalon at this stage. At this level, the dorsolateral $(D L)$, dorsomedial $(D M)$, and ventromedial $(V M)$ oculomotor subnuclei can also be distinguished. The section was stained with unheated formal-thionin. $B$, Tracing of a section through the entire head and eyes of an ED 7-8 embryo, indicating the extent of the lesions in the region of the midbrain of four randomly selected operated embryos. The location of the AON is indicated schematically to show that all four lesions completely ablated this nucleus. The shape of the brain is distorted in the section due to the variable fixation of the eyes $(E)$. The eyes were included for orientation and so that the morphological appearance of the ciliary ganglion, which lies immediately adjacent to the eye, could also be examined. $C$, cerebellum; $V$, ventricle. Scale bar, $5 \mu \mathrm{m}(A)$.
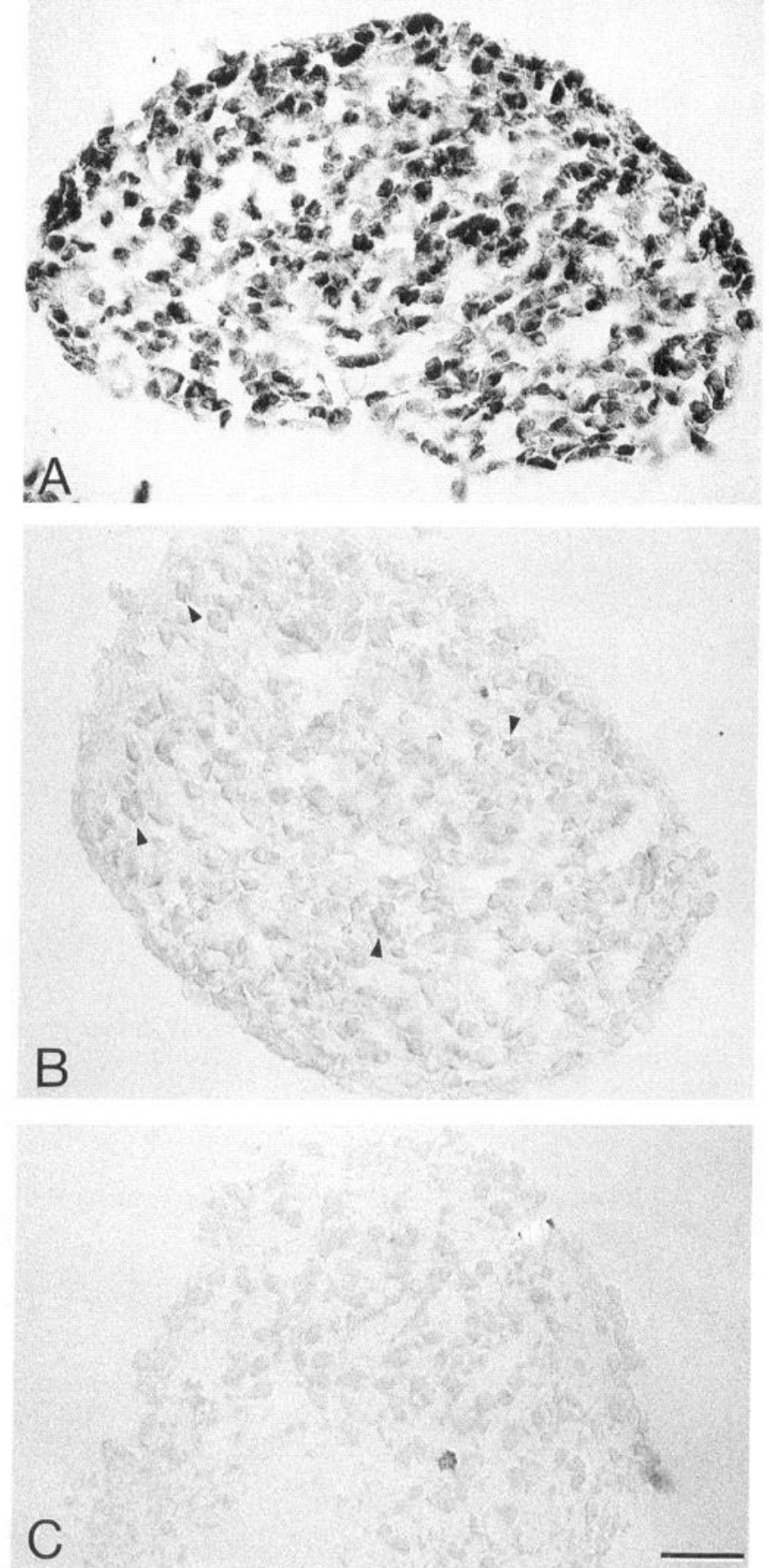

Figure 2. AChR immunolabeling of input-deprived and control chick ciliary ganglion neurons at ED 8 . Cryostat sections of ciliary ganglia from sham-operated and lesioned embryos at ED 8 were incubated with $\mathrm{mAb} 35$ followed by a biotinylated anti-rat antibody and an avidinbiotinylated HRP complex. The sections were then reacted for peroxidase activity and examined by bright-field microscopy. Most of the neuronal somata are intensely labeled in the ganglionic section from a sham-operated embryo $(A)$. The interiors of the somata are filled with HRP reaction product deposits, with the exception of the nuclei, which, when visible, are not labeled. Axons extending from the neurons are also not labeled above background levels. In contrast, practically all of the neuronal somata are lightly labeled (small arrowheads) in the ED 8 input-deprived ganglionic section $(B)$. The specificity of labeling with $\mathrm{mAb} 35$ is demonstrated by the absence of HRP reaction product deposits in the sham-operated embryo ganglionic section that was incubated with PBS in place of mAb $35(C)$. Scale bar, $50 \mu \mathrm{m}$. 


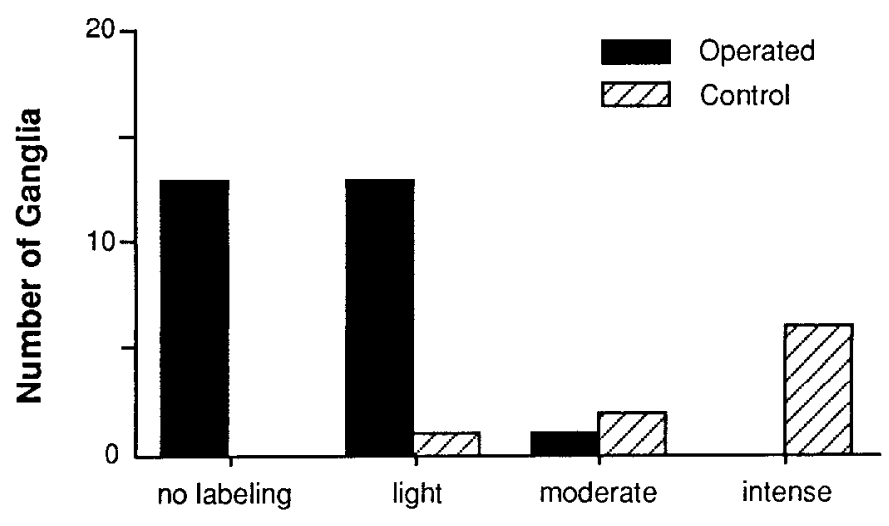

Levels of AChR Labeling

Figure 3. Distribution of ED 8 input-deprived and control ciliary ganglia among AChR labeling categories. Ganglia from normal developing and sham-operated embryos (hatched bars) and ganglia from operated embryos (solid bars) at ED 8 were processed for mAb 35 immunostaining and assigned to one of four labeling categories based on the number of labeled neurons, the intensity of labeling within individual neurons, and the relative level of $\mathrm{AChR}$ labeling across the entire cross-sectional area of the ganglion (see Materials and Methods and Results for details). The vast majority of input-deprived ganglia were either unlabeled or lightly labeled (26 of 27 input-deprived ganglia), while the majority of control ganglia, including ganglia from both normal developing and sham-operated embryos, were intensely labeled (six of nine control ganglia). No differences were observed in the levels of AChR immunolabeling in ganglia from normal developing and sham-operated embryos.

binding of mAb 35 to AChRs: ncurons in adjaccnt sections of the same ganglia were diffusely (nonspecifically) labeled at low background levels when mAb 35 was replaced with PBS (Fig. $2 C$ ) or with nonimmune rat serum at the equivalent $\operatorname{IgG}$ concentration.

In comparison to ED 8 control ganglia, the levels of $\mathrm{AChR}$ immunolabeling were dramatically reduced in ganglionic neurons from ED 8 operated embryos. The vast majority of the neurons in input-deprived ganglia were either unlabeled or lightly labeled (Fig. $2 B$ ). However, the localization of HRP reaction product within the individual neurons was not altered. These differences in the levels of AChR labeling cannot be attributed to treatment differences, since ciliary ganglia from operated and control embryos were processed in parallel in all experiments, and each slide had sections from age-matched input-deprived and control ganglia.

To provide a morc quantitative comparison of AChR levels in neurons of operated and control ganglia, ganglia were assigned to one of four labeling categories based on the number of labeled neurons, the intensity of labeling within individual neurons, and the relative level of $A C h R$ immunolabeling across the entire cross-sectional area of the ganglion. Ganglia were classified as not labeled if the vast majority of neurons contained levels of HRP reaction product similar to the amounts present in sections treated with nonimmune serum or PBS in place of $\mathrm{mAb} 35$. Ganglia were classified as lightly labeled if practically all of the neurons were lightly labeled with at most $0-10 \%$ of the neurons being moderately or intensely labeled, while in moderately labeled ganglia $10-60 \%$ of the neurons were moderately or intensely labeled. Finally, in intensely labeled ganglia, $75 \%$ or more of the neurons were intensely labeled. Forty-eight percent of the ganglia from ED 8 operated embryos were scored as not labeled, and another $48 \%$ were judged to be lightly labeled (Fig. 3 ). One ganglion, representing $4 \%$ of the ED 8 input-deprived ganglia that were scored, was assigned to the moderately labeied category since a small region of the ganglion contained moderately to intensely labeled neurons (Fig. 3). No ganglia from operated embryos were intensely labeled.

Ganglia from control embryos distributed differently among the labeling categories with a clear skew toward categories of heavier labeling compared with that found for input-deprived ganglia (Fig. 3). Twenty-two percent of the control ganglia were moderately labeled, and $67 \%$ were intensely labeled. In the case of the moderately labeled control ganglia, the AChR immunolabeling did not resemble the staining pattern seen in the one moderately labeled input-deprived ganglion, since the majority of the neurons were moderately labeled in the control ganglia. One ganglion, representing $11 \%$ of the ED 8 control ganglia, was scored as lightly labeled, and no control ganglia were scored as not labeled.

\section{Expression of three other proteins in control and input- deprived neurons on ED 8}

The relative levels of three other neuronal components were compared in ciliary ganglia from operated and control embryos at ED 8 to establish the specificity of the decline in AChRs. Immunolabeling for one of the components, SV2, a synaptic vesicle glycoprotein, was also used to look for the presence of presynaptic terminals in ganglia from operated embryos in order to establish the effectiveness of the operation. Normally, at early developmental stages, SV2 immunolabeling is present throughout the preterminal neurites and growth concs of ncurons, bccoming progressively restricted to the presynaptic terminal over time (Lupa and Hall, 1989). In ciliary ganglia from ED 8 control embryos, anti-SV2 stained granular and rod-like structures were scattered throughout the cross-sectional area, and thin patches of staining were also present immediately adjacent to a portion of the surface of most neurons (Fig. 4A). These stained structures are thought to represent preterminal neurites and presynaptic terminals, respectively, that are derived from neurons of the AON. While these anti-SV2-stained structures were readily detected in all ED 8 control ganglion sections, they were generally not observed on the surface of neurons in ganglia from ED 8 operated embryos (Fig. $4 B$ ), demonstrating the absence of presynaptic terminals in operated ganglia. Infrequently, however, very small patches of anti-SV2 staining were detected adjacent to the surface of a small number of neurons in a few ED 8 operated ganglia.

Anti-SV2 immunolabeling was also present in the somata of neurons from both input-deprived and control ganglia at ED 8, and likely represents the synthesis of synaptic vesicles in the developing neurons. Neurons from both operated and control ganglia were moderately to intensely labeled with the anti-SV2 $\mathrm{mAb}$ (Fig. 4). Thus, neuronal somata of input-deprived and control ganglia contained essentially equivalent levels of immunoreactivity for SV2. Further, the high levels of anti-SV2 immunolabeling in neurons from ED 8 lesioned embryos contrasted to the low levels of AChR labeling in the same cells in adjacent cryostat sections.

Similarly, in contrast to the dramatic difference in AChR levels in neurons of input-deprived and control ganglia, there were no significant differences in the relative levels of two major cytoskeletal proteins, MAP $1 \mathrm{~B}$ and MAP 2, in neuronal somata 

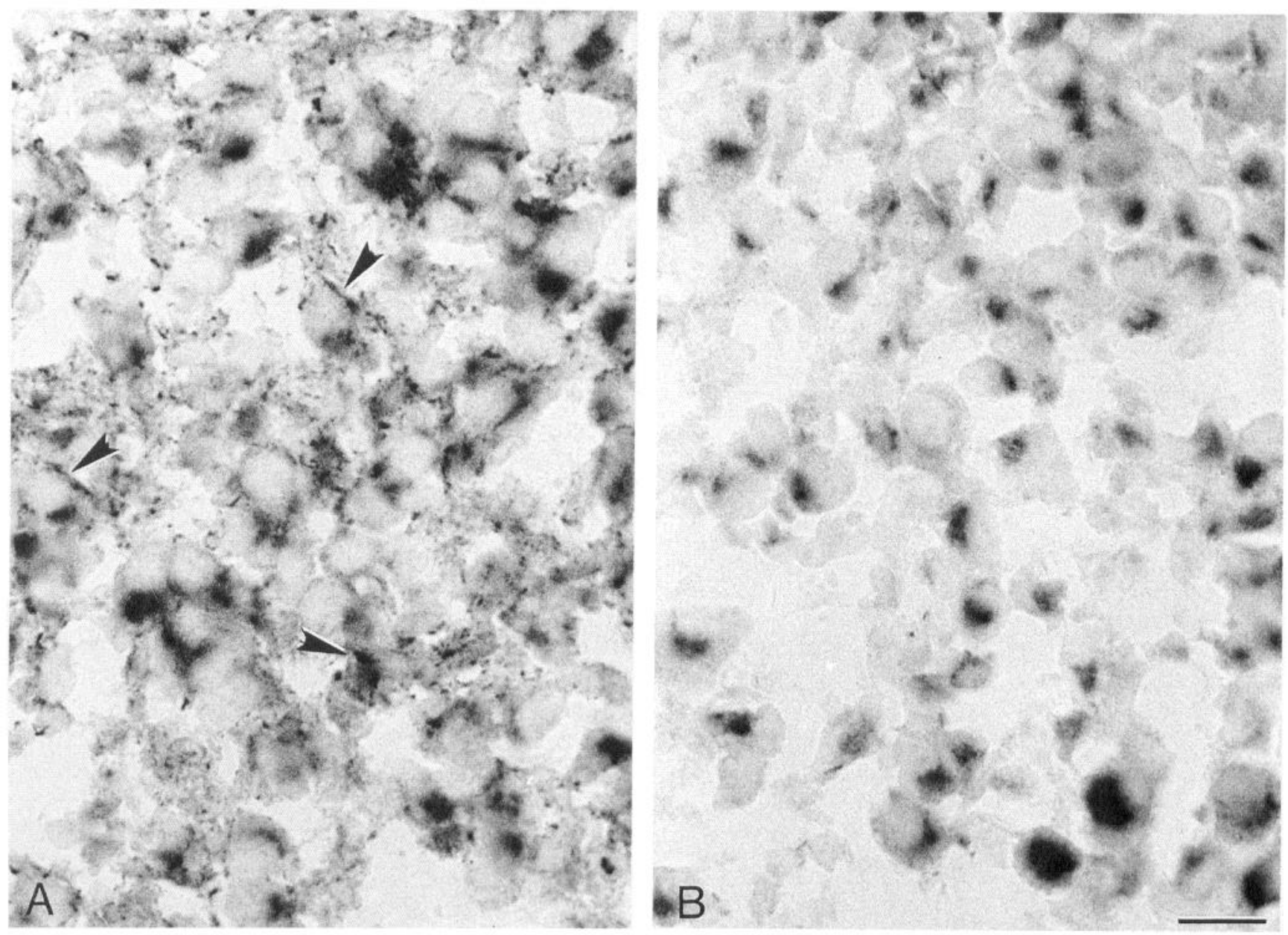

Figure 4. Synaptic vesicle protein immunolabeling of ciliary ganglion sections from operated and control chick embryos at ED 8 . Cryostat sections of ciliary ganglia from sham-operated and lesioned ED 8 embryos were immunolabeled with anti-SV2, an mAb to a synaptic vesicle transmembrane glycoprotein. The bound $\mathrm{mAb}$ was detected by using a biotinylated anti-mouse antibody and an avidin-biotinylated HRP complex. Thin patches of anti-SV2 labeling (arrowheads) are present immediately adjacent to a portion of the surface of most neurons in the control ganglion section ( $A$ ). Most of these labeled patches are presynaptic terminals. In addition, anti-SV2-stained granular and rod-like structures are scattered throughout the cross-sectional area of the ganglion, and are thought to represent preterminal neurites derived from neurons of the AON. In contrast, in the input-deprived ganglion section $(B)$, no anti-SV2-stained structures are located on the surface of the neurons, and no anti-SV2-stained granular structures are present throughout the cross-sectional area. Similar levels of anti-SV2 immunolabeling are present, however, in the cytoplasm of most input-deprived and control innervated neurons, and likely represent the synthesis of synaptic vesicles in the developing neurons. Scale bar, $16 \mu \mathrm{m}$.

of input-deprived and control ganglia at ED 8. Normally, MAP $1 \mathrm{~B}$ is highly concentrated in developing axonal processes and is also present in the soma of neurons (Schoenfeld et al., 1989). MAP 2 is predominantly present in the dendrites and soma of developing neurons (Bernhardt and Matus, 1984; DeCamilli et al., 1984; Sims et al., 1988; Schoenfeld et al., 1989). In ganglia from both lesioned and control embryos, neuronal somata and dendritic processes were moderately to intensely immunolabeled with mAb MAP 2 (Fig. 5). Following immunolabeling with mAb MAP 1B-2, neuronal somata and axons were densely filled with HRP reaction product in both input-deprived and control ganglia.

In all cases, the labeling observed with the anti-SV2, MAP $1 \mathrm{~B}-2$, and MAP $2 \mathrm{mAbs}$ is likely to represent the specific binding of the antibodies to their epitopes because only nonspecific labeling was observed in ganglia from ED 8 lesioned or control embryos when these mAbs were replaced with either nonimmune mouse serum at an equivalent $\mathrm{IgG}$ concentration or with PBS.

\section{Developmental expression of AChRs in control and input- deprived neurons}

Although ED 8 is the optimal age for establishing the effects of removing the presynaptic inputs on $\mathrm{AChR}$ expression in ciliary ganglion neurons, $\mathrm{AChR}$ levels were also examined in neurons of input-deprived and control ganglia at stages ranging from ED 5 to ED 12 to determine whether AChR levels change over time in neurons developing in the absence of innervation. Ganglia from control and operated embryos were processed for AChR immunolabeling with $\mathrm{mAb} 35$ on ED 5, 6, 7, 10, and 12. Ganglia from both lesioned and control ED 8 embryos were also included in each of these experiments as a standard for comparison and as a control for any small interexperimental differences in the intensity of mAb 35 immunostaining. In addition, input-deprived and control ganglia were immunolabeled with anti-SV2, MAP 1B-2, and MAP $2 \mathrm{mAbs}$ at these developmental stages.

In ganglia from control embryos, there were increases both in the number of immunoreactive neurons and in the intensity 

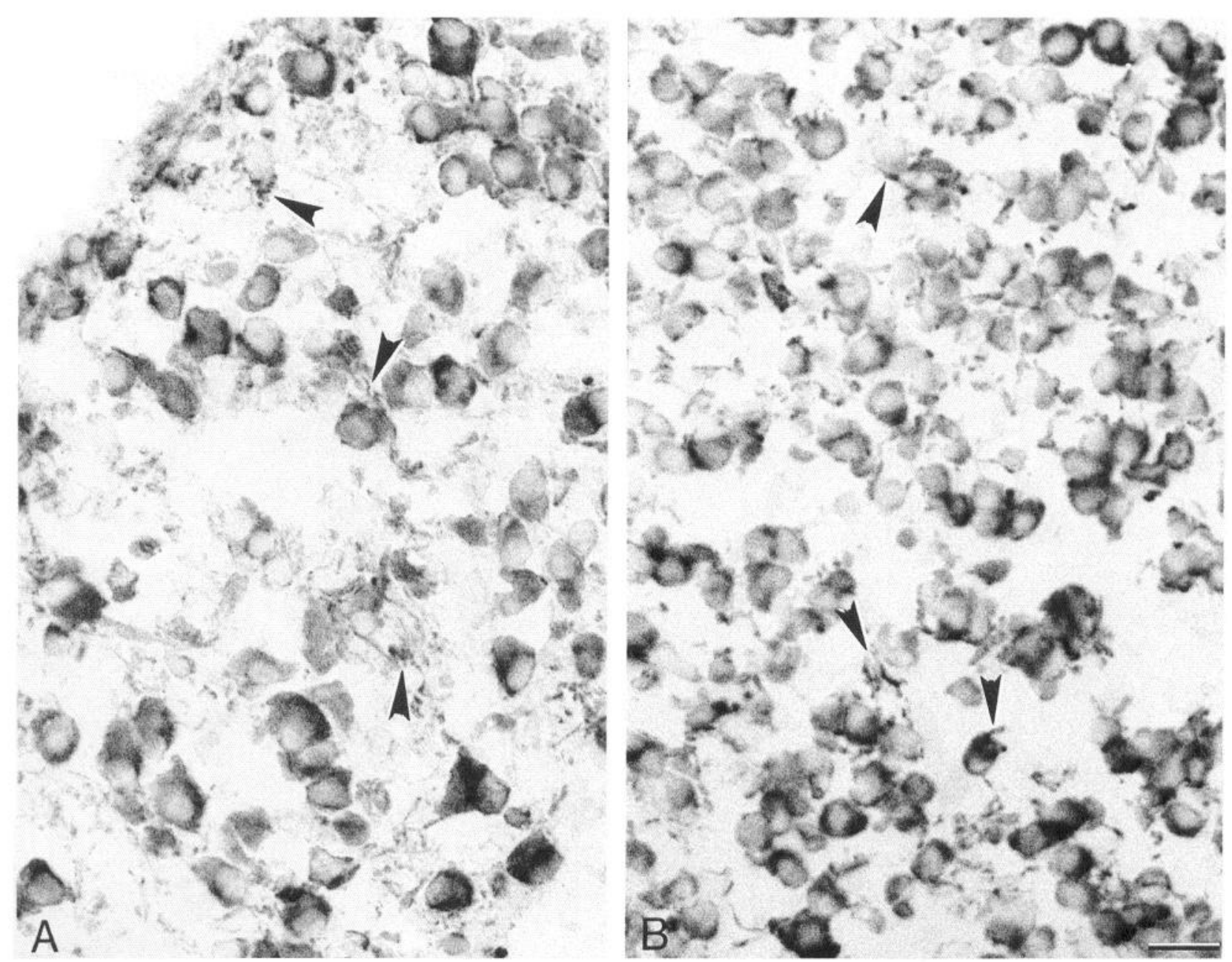

Figure 5. MAP 2 immunolabeling of input-deprived and control chick ciliary ganglion neurons at ED 8. Cryostat sections of ciliary ganglia from sham-operated and lesioned ED 8 embryos were incubated with an anti-MAP 2 mAb and the bound mAb was detected by immunoperoxidase labeling. The anti-MAP 2 mAb binds to MAP 2, which is predominantly present in the dendrites and the soma of developing neurons. Similar levels of MAP 2 immunolabeling are present in ganglionic sections from sham-operated $(A)$ and lesioned $(B)$ embryos. Moderate or intense labeling fills a portion of the cytoplasm and the dendritic processes (arrowheads) of both input-deprived and control ganglion neurons. Scale bar, $31 \mu \mathrm{m}$.

of $\mathrm{AChR}$ labeling within individual neurons from ED 5 to $\mathrm{ED}$ 12 (Fig. $6 A, B$ ), which is consistent with the findings of previous immunocytochemical, biochemical, and electrophysiological studies of the normal developmental expression of AChRs in chick ciliary ganglion neurons (Smith et al., 1985; Margiotta and Gurantz, 1989; Engisch and Fischbach, 1990; Jacob, 1991). In ganglia from operated embryos, the levels of AChR immunolabeling were consistently lower than control levels at every stage of development examined. A total of 75 ganglia from lesioned embryos on ED 5-12 were analyzed; $96 \%$ of these ganglia had reduced levels of $\mathrm{AChR}$ labeling as compared to the levels present in ganglia from age-matched control embryos $(n=56)$.

To evaluate quantitatively the levels of $\mathrm{AChR}$ labeling in neurons of input-deprived and control ganglia from ED 5 to ED 12 , an index of AChR labeling intensity was calculated for ganglia at each developmental age. This involved scoring ganglia at each age as belonging to one of four labeling categories as described above, assigning a numerical value to each of the labeling categories [no labeling (1), light labeling (2), moderate labeling (3), and intense labeling (4)], multiplying each value by the proportion of ganglia in the category, and then summing the four determinations. The calculated indices of AChR labeling intensity were lower for input-deprived ganglia as compared to control ganglia at each developmental age (Table 1). At ED 5, 6, and 12, however, the differences in the intensity of labeling between neurons of input-deprived and control ganglia

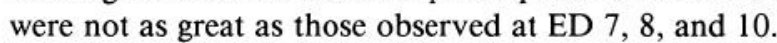

In normal developing ganglia, synapse formation begins at ED 4.5 and less than $50 \%$ of the neurons have synaptic terminals on their surface at ED 5 (Jacob, 1991). Eighty percent of the ganglia from ED 5 control embryos were lightly immunolabeled with mAb 35: the cytoplasm of many of the neurons contained at least some HRP reaction product (Table 1). In contrast, all of the ganglia from ED 5 operated embryos were unlabeled: the cytoplasm of the vast majority of neurons contained only background levels of HRP reaction product. At ED 6, there was an increase in the levels of AChR labeling over the levels observed at ED 5 in ganglia from both operated and control embryos. However, the increase in input-deprived ganglia was much less than that seen in control ganglia from ED 5 to ED 6 (Table 1). Seventy percent of the input-deprived ganglia were lightly la- 

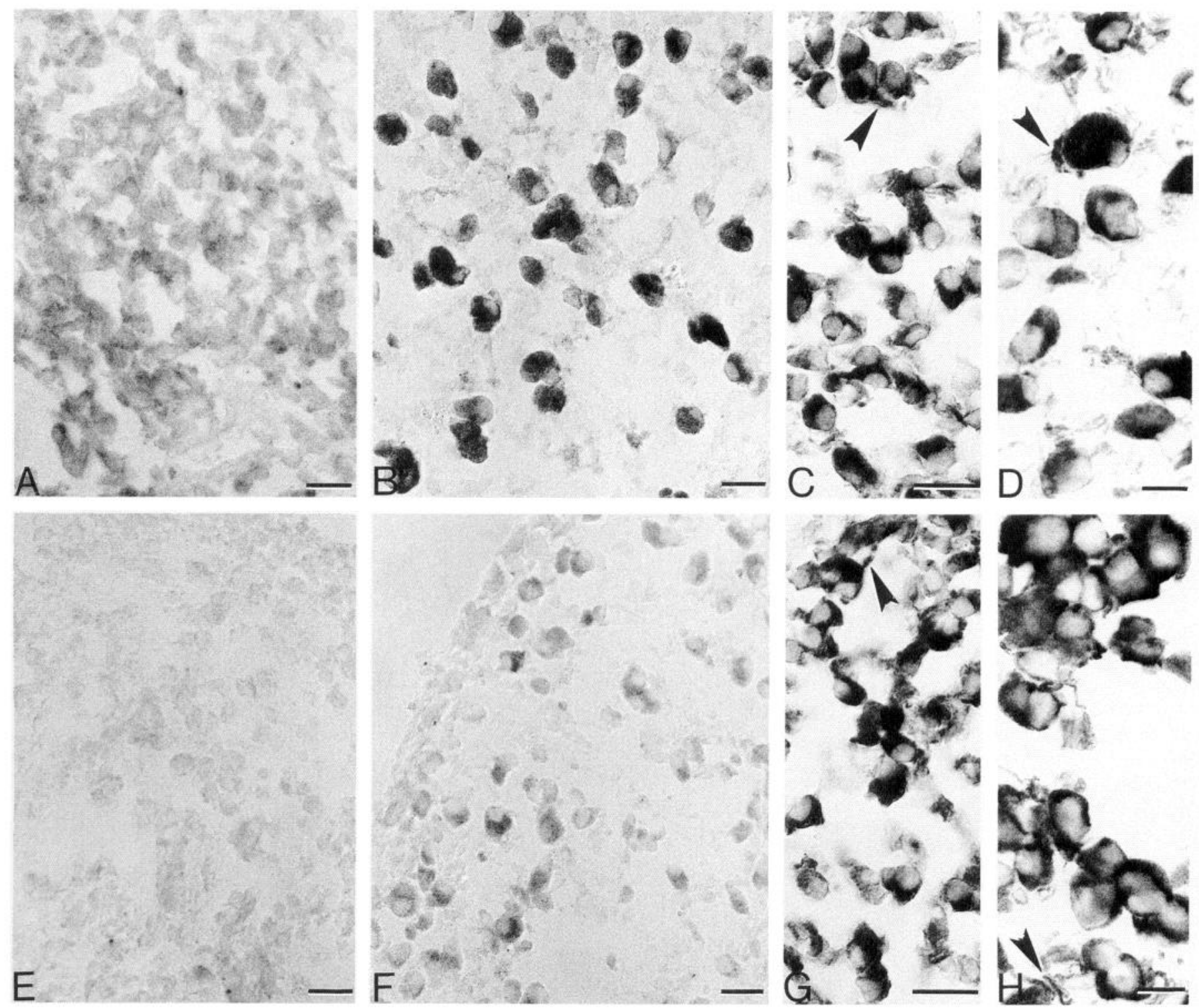

Figure 6. AChR and MAP 2 immunolabeling of input-deprived and control chick ciliary ganglion neurons at ED 6 and 12 . Cryostat sections of ciliary ganglia from sham-operated and lesioned embryos at ED 6 and 12 were immunolabeled with mAb 35 to detect AChRs $(A, B, E, F)$ or with an anti-MAP $2 \mathrm{mAb}(C, D, G, H)$. Most of the neuronal somata are moderately labeled with mAb 35 in the ED 6 control ganglion section $(A)$, whereas the majority of the neuronal somata are lightly labeled in the ED 6 input-deprived ganglion section $(E)$. In comparison, intense AChR labeling fills the cytoplasm of most neuronal somata in the ED 12 control ganglion section $(B)$, while the neuronal somata are lightly or moderately labeled in the ED 12 input-deprived ganglion section $(F)$. In contrast, at both $\operatorname{ED} 6(C, G)$ and $\operatorname{ED} 12(D, H)$, control $(C, D)$ and input-deprived $(G, H)$ neurons have essentially equivalent levels of MAP 2 immunoreactivity. Intense labeling is present in the somata and the dendrites (arrowheads). At ED 12, the soma labeling is heaviest in a peripheral portion of the cytoplasm in many of the input-deprived $(H)$ and control $(D)$ ganglion neurons. In both AChR and MAP 2-immunolabeled neurons, the nuclei, when visible, are not labeled. Scale bars, $19 \mu \mathrm{m}$.

beled with $\mathrm{mAb} 35$ at ED 6, while the remaining ganglia still appeared unlabeled (Fig. $6 E$ ). Further, in contrast to the steady increases in the overall intensity of HRP staining in control ganglia from ED 6 to ED 12, all of the ganglia from lesioned embryos were either unlabeled or lightly labeled with $\mathrm{mAb} 35$ through ED 10 (Figs. $6 A, B, E ; 7 B$ ). In comparison, no control ganglia were unlabeled and only one ganglion was lightly labeled at these stages. At ED 12, the amount of reaction product in ganglia from lesioned embryos increased: $60 \%$ of the ganglia were lightly labeled, $40 \%$ were moderately labeled, and no ganglia were unlabeled (Fig. $6 F$, Table 1).

At these later stages of development, from ED 8.5 to ED 14, input-deprived and control ganglion neurons are establishing synaptic contacts with the target tissue (Landmesser and Pilar, 1974; Furber et al., 1987; Meriney and Pilar, 1987; Pilar et al., 1987). In addition, cell death, and enhanced cell death in the case of input-deprived ganglia, occurs during this period. Although cell counts were not done, the number of neurons was reduced in both input-deprived and control ganglia at ED 10 and 12. For example, ED 12 input-deprived ganglia had about half of the number of neurons in ED 12 control ganglia (see Furber et al., 1987). Consequently, the increase in AChR labeling in ganglia from ED 12 lesioned embryos occurred in the few surviving neurons, which were lightly or moderately labeled with $\mathrm{mAb} 35$ (Fig. $6 F$ ). In contrast, in $65 \%$ of the ED 10 and $90 \%$ of the ED 12 control ganglia, $75 \%$ or more of the neurons 


\begin{tabular}{lll}
\hline Table 1. Index of AChR labeling intensity & \\
Ciliary & \multicolumn{1}{l}{ Labeling index } & \\
ganglion & Input-deprived & \\
age & ganglia & Control ganglia \\
\hline ED 5 & $1.00(6)$ & $1.80(5)$ \\
ED 6 & $1.72(7)$ & $3.17(6)$ \\
ED 7 & $1.27(11)$ & $3.50(4)$ \\
ED 8 & $1.55(27)$ & $3.56(9)$ \\
ED 10 & $1.21(19)$ & $3.67(21)$ \\
ED 12 & $2.40(5)$ & $3.91(11)$
\end{tabular}

An index of AChR labeling intensity was constructed for both input-deprived and control ciliary ganglia at each of the developmental ages listed above. Ganglia were assigned to labeling categories based on the criteria described in Materials and Mcthods. The proportion of ganglia in each category was then multiplied by the number assigned to that category [no labeling (1), light labeling (2), moderate labeling (3), and intense labeling (4)] and these values were summed for inputdeprived or control ganglia at each developmental age listed. Numbers in parentheses are the total numbers of ganglia used to calculate their respective labeling indices. At all ages examined, the calculated indices of $A C h R$ labeling intensity are lower for input-deprived ciliary ganglia as compared to control ganglia. At ED 5, 6, and 12, the differences in the intensity of labeling between neurons of input-deprived and control ganglia are less than those observed at ED 7, 8, and 10 .

were very intensely labeled (Fig. $6 \mathrm{~B}$ ). In the remaining ED 10 and 12 control ganglia, more of the neurons were only moderately labeled, possibly due to the onset of naturally occurring cell death in those particular cells.

While AChR expression was dramatically altered in ciliary ganglion neurons developing in situ in the absence of innervation, the developmental expression of three other neuronal proteins, SV2, MAP 1B, and MAP 2, did not appear to be affected, at least until ED 10. Thus, neurons of input-deprived and control ganglia had equivalent levels of immunoreactivity for SV2, MAP 1B, and MAP 2 from ED 5 up to ED 10, with the neuronal somata staining intensely for MAP $1 \mathrm{~B}$ and MAP 2 as early as ED 6 (Figs. 4, 5, 6C, $G$ ). At ED 10, however, the intensity of SV2, MAP 1B, and MAP 2 immunolabeling was reduced in some neurons of both input-deprived and control ganglia. In ganglia from operated embryos at ED 10, a greater number of the neurons were less stained as compared to the neurons in control ganglia, presumably due to the greater amounts of cell death. The remaining neurons were intensely labeled with either the anti-SV2, MAP 1B-2, or MAP $2 \mathrm{mAb}$ in ganglia from both operated and control embryos (Fig. 7A,C). At ED 12, most of the neurons in input-deprived ganglia had levels of SV2, MAP $1 \mathrm{~B}$, and MAP 2 immunostaining that were comparable to those observed in ED 12 control ganglion neurons (Fig. $6 D, H$ ).

To compare directly the levels of $\mathrm{AChR}$ labeling and the levels of SV2, MAP 1B, and MAP 2 immunolabeling in neurons of input-deprived ganglia at the selected developmental stages, in as many cases as possible, serial sections of the same ganglion were processed for immunostaining with all four mAbs. Thus, neurons expressing low levels of AChRs were shown to have high levels of SV2, MAP 1B, and MAP 2 immunolabeling (Fig. 7), demonstrating the specificity of the reduction in AChR expression and the good health of the majority of neurons present at each stage.

\section{Discussion}

The major finding reported here is that AChR levels are dramatically reduced in developing chick ciliary ganglion neurons in situ when innervation is prevented by the surgical removal of the preganglionic nucleus prior to the time of synapse formation. In contrast, the relative levels of soma labeling for three other components, SV2, MAP 1B, and MAP 2, are not different in neurons of input-deprived and control ganglia from ED 5 up to ED 10. The results demonstrate that signals from the presynaptic input specifically increase $\mathrm{AChR}$ levels in developing neurons in situ.

The effectiveness of the operation in completely ablating afferents to the ciliary ganglion was established by a number of criteria: (1) the midbrain was reduced in size following the operation as determined by gross inspection; (2) the AON was not present in serial paraffin sections of the brain; (3) ciliary ganglia had either no preganglionic nerve or a very fine, wispy process at the time of dissection; and (4) anti-SV2-immunolabeled preterminal neurites and synaptic terminals were not readily detected in the ganglia. Based on these criteria, the majority of neurons in all of the ganglia from operated embryos had no detectable innervation. In a few ganglia, however, very small patches of anti-SV2 labeling were observed adjacent to the surface of a small number of neurons. These stained structures could represent preterminal neurites extending from the ciliary ganglion neurons toward their target tissues in the eye, or the possible presence of synapses on the neurons. Such synapses could explain why a small number of neurons were occasionally observed to have moderate or intense levels of $\mathrm{AChR}$ labeling in ganglia from operated embryos, while the majority of neurons had little or no $\mathrm{AChR}$ labeling. At the ultrastructural level, morphologically specialized synapses have previously been observed to be present, although rare, on the surface of the neurons following ablation of the AON (Furber et al., 1987; Engisch and Fischbach, 1992). Possiblc sources of this innervation include residual neurons of the AON that were not removed by the operation, and aberrant intraganglionic synapses. Aberrant intraganglionic synapses have been reported to form on adult rabbit ciliary ganglion neurons following denervation (Johnson, 1988). Chick ciliary ganglion neurons establish synapses on one another in dissociated cell culture, but not in vivo under normal circumstances or following denervation (Margiotta and Berg, 1982; Jacob and Berg, 1988). Regardless of the source, in the present study, innervation occurred infrequently, if at all, and involved a very minor portion of the total neuron population in a few operated ganglia.

AChR levels were compared in neurons of input-deprived and control ganglia by indirect immunocytochemical labeling of frozen ganglion sections. This labeling method detects AChRs in the internal pool of the neurons. Surface AChRs, which occupy a small proportion of the total cell surface in innervated neurons (Cantino and Mugnaini, 1975; Jacob et al., 1984, 1986; Loring and Zigmond, 1987; Jacob, 1991), are less readily detected due to the thinness of the frozen section. In normal developing chick ciliary ganglion neurons, approximately two-thirds of the total AChRs are intracellular, and these AChRs are predominantly associated with the rough endoplasmic reticulum (Jacob et al., 1986; Stollberg and Berg, 1987; Jacob, 1991). Thus, the reduced amounts of AChR immunolabeling in neuronal somata of input-deprived ganglia as compared to control ganglia suggest that fewer AChRs are synthesized in neurons developing in the absence of innervation. The possibility cannot be ruled out, however, that AChRs are synthesized at normal levels but rapidly degraded in input-deprived neurons.

The reduction in AChRs is specific in that it does not reflect a general change in the synthetic capabilities or health of the 
neurons as indicated by the essentially equivalent levels of SV2, MAP 1B, and MAP 2 immunoreactivity in neuronal somata of input-deprived and control ganglia prior to ED 10. SV2 immunolabeling in the soma represents the synthesis of synaptic vesicles in developing neurons that are extending axons and establishing synaptic contacts with their targets (Greif and Reichardt, 1982; Bixby and Reichardt, 1985; Chun and Shatz, 1988). Similarly, MAP 1B and MAP 2 immunoreactivity in the somata of embryonic neurons likely represents the synthesis of these two MAPs, which subsequently accumulate in axonal processes and dendrites of developing neurons, respectively (Bernhardt and Matus, 1984; Burgoyne and Cumming, 1984; DeCamilli et al., 1984; Bloom et al., 1985; Sims et al., 1988; Schoenfeld et al., 1989). All three components are sensitive indicators of the general state of the neurons: their distribution and levels change in neurons with differentiation and maturation (Burgoyne and Cumming, 1984; Alaimo-Beuret and Matus, 1985; Kumagai et al., 1985; Kosik and Finch, 1987; Lupa and Hall, 1989; Schoenfeld et al., 1989; Dahm and Landmesser, 1991). Thus, the demonstration of high levels of SV2, MAP 1B, and MAP 2 immunolabeling in input-deprived neuronal somata expressing low levels of AChR labeling following the immunostaining of serial sections establishes the healthy state of these neurons from ED 6 up to ED 10. At ED 10 and to a lesser extent at ED 12, reductions were observed in the intensity of SV2, MAP $1 \mathrm{~B}$, and MAP 2 immunolabeling in a subpopulation of neurons in both operated and control ganglia. The reduced staining probably reflects the onset of cell death in those particular cells. From ED 9 to ED 14, ciliary ganglion neurons undergo programmed cell death with a greater number of neurons dying in deafferented ganglia (Landmesser and Pilar, 1974; Furber et al., 1987). The rest of the neuron population in both operated and control ganglia at ED 10 and 12 appears to be healthy: these neurons had relatively intense and essentially equivalent levels of SV2, MAP $1 \mathrm{~B}$, and MAP 2 immunostaining. Moreover, the increase in AChR labeling in input-deprived ganglia at ED 12 further establishes the viability of the surviving neurons.

Although these results demonstrate that signals from the presynaptic input specifically increase AChR levels in developing neurons in situ, it is clear that AChR expression is not totally dependent upon innervation. Low levels of AChR immunolabeling were detected in input-deprived neurons. Further, recent studies have demonstrated that the whole-cell $\mathrm{ACh}$ response of acutely dissociated neurons from input-deprived ciliary ganglia is not significantly different from control neuron values at ED 14 and 18 (Engisch and Fischbach, 1992). We have obtained similar results in preliminary studies of the ACh sensitivity of

\footnotetext{
Figure 7. AChR, MAP 2, and MAP 1B immunolabeling of serial ciliary ganglion sections from an ED 10 operated embryo. Serial cryostat sections of an input-deprived ED 10 ciliary ganglion were immunolabeled with an anti-MAP $2 \mathrm{mAb}(A)$, mAb $35(B)$, or an anti-MAP $1 \mathrm{~B}-2$ $\mathrm{mAb}(C)$ to compare the relative levels of the three components in neurons of the same ganglion. mAb MAP 1B-2 binds to MAP 1B, which is highly concentrated in axonal processes and is present in the soma of developing neurons. Most of the neuronal somata are intensely labeled with the anti-MAP $2(A)$ and anti-MAP $1 \mathrm{~B}(C) \mathrm{mAbs}$, while the neurons are only lightly labeled with mAb $35(B)$. Some anti-MAP 1B-2 $\mathrm{mAb}$-labeled axonal processes (arrowheads) can be detected $(C)$. Further, there is cell death in the ganglion at this age, which may explain the low levels of MAP 2 and MAP 1B immunostaining in a few of the neurons (arrows, $A, C$ ). Scale bar, $34 \mu \mathrm{m}$.
}
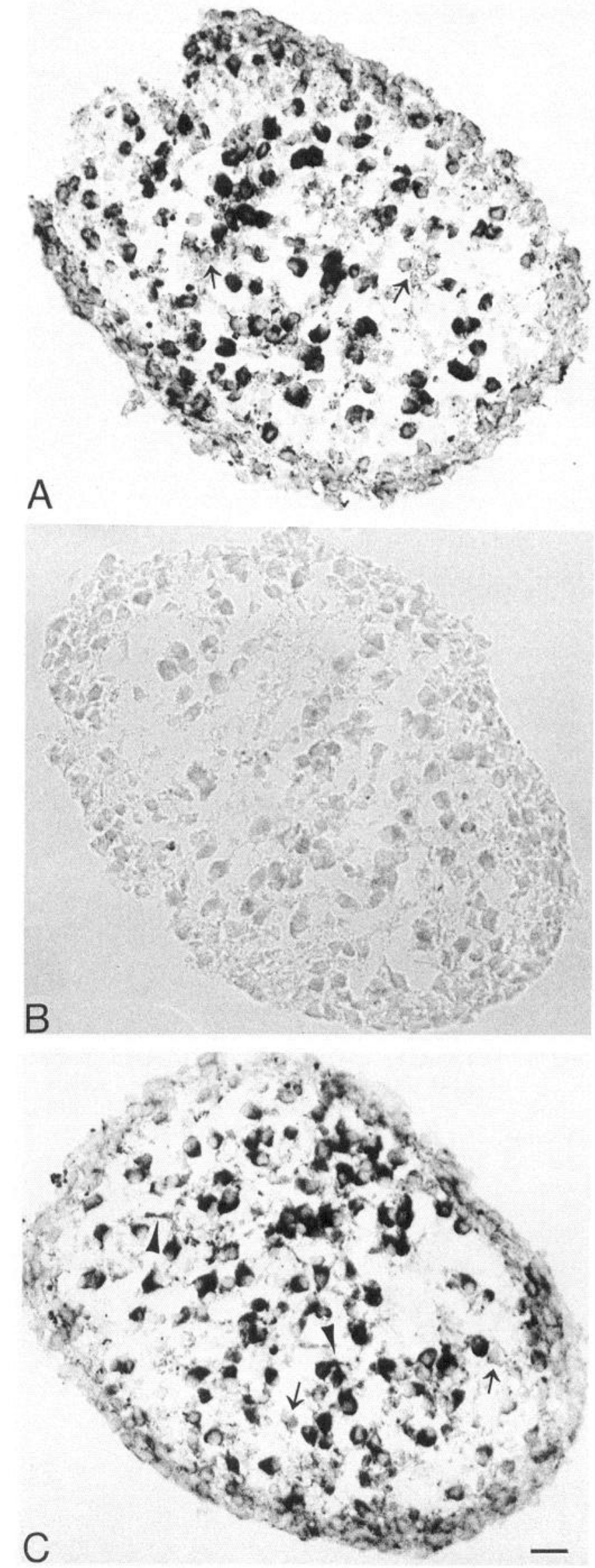
acutely dissociated input-deprived and control ganglion neurons at ED 9-14, with the response being measured as the peak conductance per unit membrane capacitance following microperfusion with saturating concentrations of $\mathrm{ACh}$ (J. F. Margiotta and M. H. Jacob, unpublished observations). Similarly, a reduction in internal AChR levels in the absence of a change in $\mathrm{ACh}$ sensitivity has been observed previously in ciliary ganglion neurons of newly hatched chicks following denervation (Jacob and Berg, 1987, 1988; McEachern et al., 1989). These findings can be explained by the fact that only a small proportion of the internal receptors (about $5 \%$ in developing neurons in culture) are transported to the cell surface (Stollberg and Berg, 1987). A saturable step in the processing of the AChK complex may limit transport to the surface. Additionally, some internal AChRs may be unassembled subunits as well as misassembled and partially assembled complexes that are retained and degraded in the rough endoplasmic reticulum ( $\mathrm{Gu}$ et al., 1989; Klausner, 1989; Blount et al., 1990). Thus, AChR subunits appear to be synthesized in excess in developing ciliary ganglion neurons. Moreover, only a fraction of the total number of AChRs on the surface of developing ciliary ganglion neurons are functional, although silent receptors may be converted to a functional state, possibly by a posttranslational modification (Margiotta et al., 1987a,b; Margiotta and Gurantz, 1989; Vijayaraghavan et al., 1990). Overall, these findings suggest that in both developing and mature chick ciliary ganglion neurons in situ the expression of functional AChRs on the neuron surface may not be regulated by signals from the presynaptic input. However, changes may have occurred in the total number of surface AChRs (including both functional and silent receptors), in the proportion of silent AChRs that can be converted to a functional state, and in the single-channel properties of the AChRs on the developing inputdeprived neurons that were not detected by assaying the wholecell response to saturating concentrations of $\mathrm{ACh}$. Changes in these parameters in response to innervation would have important consequences for the efficacy of synaptic transmission. Alternatively, the lack of a change in surface AChRs would demonstrate that in neurons innervation increases AChR synthesis and directs the accumulation of AChRs at the site of synapse formation (Jacob, 1991; Moss and Role, 1993), while other events (intrinsic and/or extrinsic influences) regulate the number and properties of AChRs that are expressed on the neuron surface. Such a finding would contrast to the situation in skeletal muscle, where innervation influences the transcription of the different AChR subunit genes, resulting in a change in the subunit composition and functional properties of AChRs that arc cxpressed, as wcll as an increase in the local synthesis and insertion of AChRs into the postsynaptic membrane and a decrease in extrajunctional AChRs (Schuetze and Role, 1987; Gu and Hall, 1988; Changeux, 1991; Dahm and Landmesser, 1991; Witzemann et al., 1991).

Interestingly, alterations in the levels and functional properties of surface AChRs do occur on normal developing chick ciliary ganglion neurons from ED 8 to ED 16: the ACh response per unit membrane area and the average density of surface AChRs both increase fourfold, and there are changes in the relative abundance, kinetics, and ACh affinity of AChR subtypes expressed (Margiotta and Gurantz, 1989). Recent studies of embryonic chick sympathetic ganglion neurons in culture demonstrate that innervation by the appropriate preganglionic tissue, the dorsal spinal cord, results in a 10-fold increase in $\mathrm{ACh}$ sensitivity, the appearance of a unique AChR conductance class, and an increase in the rate of appearance of AChRs on the neuron surface (Role, 1988; Moss et al., 1989; Gardette et al., 1991). These dramatic effects of innervation on AChR function and levels on the neuron surface in vitro appear to differ from the lack of a change in the ACh response of input-deprived ciliary ganglion neurons in situ (Engisch and Fischbach, 1992). The difference may be due to the fact that in the in vitro experiments the neurons are only being exposed to preganglionic tissue-derived signals, whereas in the complex in situ environment other cellular factors may also regulate AChR expression (see below). Clearly, the present study does establish a role for innervation in the regulation of $\mathrm{AChR}$ expression in developing neurons in situ: the size of the intracellular pool of AChRs is dramatically reduced in chick ciliary ganglion neurons developing in situ in the absence of innervation. Similarly, Matter et al. (1990) have demonstrated that eye enucleation prior to synapse formation prevents the 10-15-fold transient increase in AChR $\beta 2$ subunit mRNA levels that normally occurs in chick optic tectum neurons at the time of innervation.

Results from the present study further suggest that, in addition to innervation, other influences, such as retrograde signals from the target tissue, may also regulate $\mathrm{AChR}$ expression in neurons developing in situ. Specifically, AChR levels increased in the input-deprived neurons at stages that coincide with the establishment of target tissue interactions. AChRs reached detectable levels in neurons of input-deprived ganglia at ED 6. In control innervated neurons, AChR immunolabeling is present as early as ED 4.5 (Jacob, 1991). Axons of both normal developing and input-deprived ciliary ganglion neurons are present in the vicinity of the peripheral target tissue by ED 6, but it is not clear whether the myoblasts that form the striated muscles of the iris and ciliary body, the targets of the ciliary neurons, are present in the eye at this time due to controversy regarding the origin of these muscles (Furber et al., 1987; Pilar et al., 1987). Some component of the target tissue primordium may cause the increase in AChRs in deafferented neurons at ED 6. Alternatively, the increase may reflect an intrinsic developmental program of the neurons as differentiation proceeds, or it is caused by other tissues in the surrounding environment. In addition, in inputdeprived ganglia at ED 12, there was an increase in the levels of AChR immunolabeling in the few surviving neurons present. At ED 18, Engisch and Fischbach (1992) observed no detectable difference in the levels of AChR immunolabeling in input-deprived and control chick ciliary ganglion cryostat sections. At ED 12, neurons of normal developing ciliary ganglia are forming synapses on their target tissues in the eye (Landmesser and Pilar, 1974; Merincy and Pilar, 1987; Pilar ct al., 1987), and it has been established that all of the surviving neurons in ED 12 inputdeprived ganglia have at least one axonal process in the vicinity of the target structures (Furber et al., 1987). Further, the ACh sensitivity of chick ciliary ganglion neurons developing in situ in the absence of the eye is $20-50 \%$ lower than age-matched control neuron levels at ED 6-12 (Engisch and Fischbach, 1990). Recently, a $50 \mathrm{kDa}$ fraction from chick embryonic eye extract has been found to cause a 10 -fold increase in ACh sensitivity over time and a 1.5-fold increase in AChRs on ciliary ganglion neurons in culture (Halvorsen et al., 1991). A component of muscle membrane fragments has also been observed to prevent the loss of ACh sensitivity that occurs on chick ciliary ganglion neurons grown alone in culture over time (Tuttle, 1983).

Altogether, these studies demonstrate that both pre- and postganglionic tissue interactions increase AChR levels in devel- 
oping neurons in situ. We are currently extending these studies to determine the role of presynaptic inputs and retrograde signals from the target tissue in controlling the transcription of the various $\mathrm{AChR}$ subunit genes in chick ciliary ganglion neurons.

\section{References}

Alaimo-Beuret D, Matus A (1985) Changes in the cytoplasmic distribution of microtubule-associated protein 2 during the differentiation of cultured cerehellar granule cells. Neuroscience 14:1103-1115.

Bernhardt R, Matus A (1984) Light and electron microscopic studies of the distribution of microtubule-associated protein 2 in rat brain: a difference between dendritic and axonal cytoskeletons. J Comp Neurol 226:203-221.

Bixby JL, Reichardt LF (1985) The expression and localization of synaptic vesicle antigens at neuromuscular junctions in vitro. J Neurosci 5:3070-3080.

Bloom GS, Vallee RB (1983) Association of microtubule-associated protein 2 (MAP 2) with microtubules and intermediate filaments in cultured brain cells. J Cell Biol 96:1523-1531.

Bloom GS, Luca FC, Vallee RB (1985) Microtubule-associated protein IB: identification of a major component of the neuronal cytoskeleton. Proc Natl Acad Sci USA 82:5404-5408.

Blount P, McHardy MS, Merlie JP (1990) Assembly intermediates of the mouse muscle nicotinic acetylcholine receptor in stably transfected fibroblasts. J Cell Biol 111:2601-2611.

Boyd RT, Jacob MH, Couterier S, Ballivet M, Berg DK (1988) Expression and regulation of neuronal acetylcholine receptor mRNA in chick ciliary ganglia. Neuron 1:495-502.

Brehm P, Henderson LP (1988) Regulation of acetylcholine receptor channel function during development of skeletal muscle. Dev Biol 129:1-11.

Buckley K, Kelly RB (1985) Identification of a transmembrane glycoprotein specific for secretory vesicles of neural and endocrine cells. J Cell Biol 100:1284-1294.

Burgoyne RD, Cumming R (1984) Ontogeny of microtubule-associated protein 2 in rat cerebellum: differential expression of the doublet polypeptides. Neuroscience 11:157-167.

Cantino D, Mugnaini E (1975) The structural basis for electrotonic coupling in the avian ciliary ganglion. A study with thin sectioning and freeze-fracturing. J Neurocytol 4:505-536.

Changeux JP (1991) Compartmentalized transcription of acetylcholine receptor genes during motor endplate epigenesis. New Biol 3:413429.

Chun JJM, Shatz CJ (1988) Redistribution of synaptic vesicle antigens is correlated with the disappearance of a transient synaptic zone in the developing cerebral cortex. Neuron 1:297-310.

Cowan WM, Wenger E (1968) Degeneration in the nucleus of origin of the preganglionic fibers to the chick ciliary ganglion following early removal of the optic vesicle. J Exp Zool 168:105-124.

Dahm LM, Landmesser LT (1991) The regulation of synaptogenesis during normal development and following activity blockade. J Neurosci 11:238-255.

DeCamilli P, Miller PE, Navone F, Theurkauf WE, Vallee RB (1984) Distribution of microtubule-associated protein 2 in the nervous system of the rat studied by immunofluorescence. Neuroscience 11:819846.

Donovick PJ (1974) A metachromatic stain for neural tissue. J Stain Technol 49:49-51.

Engisch KL, Fischbach GD (1990) The development of ACH- and GABA-activated currents in normal and target-deprived embryonic chick ciliary ganglia. Dev Biol 139:417-426.

Engisch KL, Fischbach GD (1992) The development of $\mathrm{ACH}$ - and GABA-activated currents in embryonic chick ciliary ganglion neurons in the absence of innervation in vivo. J Neurosci 12:1115-1125.

Fambrough DM (1979) Control of acetylcholine receptors in skeletal muscle. Physiol Rev 59:165-227.

Furber S, Oppenheim RW, Prevette D (1987) Naturally-occurring neuron death in the ciliary ganglion of the chick embryo following removal of preganglionic input: evidence for the role of afferents in ganglion cell survival. J Neurosci 7:1816-1832.

Gardette R, Listerud MD, Brussaard AB, Role LW (1991) Develop- mental changes in transmitter sensitivity and synaptic transmission in embryonic chicken sympathetic neurons innervated in vitro. Dev Biol 147:83-95.

Greir KF, Reichardt LF (1982) Appearance and distribution of neuronal cell surface and synaptic vesicle antigens in the developing rat superior cervical ganglion. J Neurosci 2:843-852.

Gu Y, Hall Z (1988) Immunological evidence for a change in subunits of the acetylcholine receptor in developing and denervated rat muscle. Neuron 1:117-125.

Gu Y, Ralston E, Murphy-Erdosh C, Black RA, Hall ZW (1989) Acetylcholine receptor in a $\mathrm{C} 2$ muscle cell variant is retained in the endoplasmic reticulum. J Cell Riol 109:729-738

Halvorsen SW, Berg DK (1987) Affinity labeling of neuronal acetylcholine receptor subunits with an $\alpha$-neurotoxin that blocks receptor function. J Neurosci 7:2547-2555.

Halvorsen SW, Berg DK (1990) Subunit composition of nicotinic acetylcholine receptors from chick ciliary ganglia. J Neurosci 10:17111718 .

Halvorsen SW, Schmid HA, McEachern AE, Berg DK (1991) Regulation of acetylcholine receptors on chick ciliary ganglion neurons by components from the synaptic target tissue. J Neurosci 1 1:2177-2186.

Hamburger V, Hamilton HL (1951) A series of normal stages in the development of the chick embryo. J Morphol 88:49-92.

Jacob MH (1991) Acetylcholine receptor expression in developing chick ciliary ganglion neurons. J Neurosci 11:1701-1712.

Jacob MH, Berg DK (1987) Effects of preganglionic denervation and postganglionic axotomy on acetylcholine receptors in the chick ciliary ganglion. J Cell Biol 105:1847-1854.

Jacob MH, Berg DK (1988) The distribution of acetylcholine receptors in chick ciliary ganglion neurons following disruption of ganglionic connections. J Neurosci 8:3838-3849.

Jacob MH, Berg DK, Lindstrom JM (1984) Shared antigenic determinant between the Electrophorus acetylcholine receptor and a synaptic component on chicken ciliary ganglion neurons. Proc Natl Acad Sci USA 81:3223-3227.

Jacob MH, Lindstrom JM, Berg DK (1986) Surface and intracellular distribution of a putative neuronal acetylcholine receptor. J Cell Biol 103:205-214.

Johnson DA (1988) Regulation of intraganglionic synapses among rabbit parasympathetic neurones. J Physiol (Lond) 397:51-62.

Klausner RD (1989) Architectural editing: determining the fate of newly synthesized membrane proteins. New Biol 1:3-8.

Kosik KS, Finch EA (1987) MAP 2 and tau segregate into morphologically distinct domains after the elaboration of morphologically distinct neurites: an immunocytochemical study of cultured rat cerebrum. J Neurosci 7:3142-3153.

Kumagai H, Imazawa M, Miyamoto K (1985) Developmental changes in components of chick brain microtubule-associated protein-1 (MAP1) and tau proteins. J Biochem 97:529-532.

Landmesser L, Pilar G (1972) The onset and development of transmission in the chick ciliary ganglion. J Physiol (Lond) 222:691-713.

Landmesser L, Pilar G (1974) Synaptic transmission and cell death during normal ganglionic development. J Physiol (Lond) 241:737749.

Landmesser L, Pilar G (1978) Interactions between neurons and their targets during in vivo synaptogenesis. Fed Proc 37:2016-2022.

Loring RH, Zigmond RE (1987) Ultrastructural distribution of ${ }^{125} \mathrm{I}-$ toxin $F$ binding sites on chick ciliary neurons: synaptic localization of a toxin that blocks ganglionic nicotinic receptors. J Neurosci 7:21532162.

Lupa MT, Hall ZW (1989) Progressive restriction of synaptic vesicle protein to the nerve terminal during development of the neuromuscular junction. J Neurosci 9:3937-3945.

Margiotta JF, Berg DK (1982) Functional synapses are established between ciliary ganglion neurones in dissociated cell culture. Nature 296:152-154.

Margiotta JF, Gurantz D (1989) Changes in the number, function, and regulation of nicotinic acetylcholine receptors during neuronal development. Dev Biol 135:326-339.

Margiotta JF, Berg DK, Dionne VE (1987a) The properties and regulation of functional acetylcholine receptors on chick ciliary ganglion neurons. J Neurosci 7:3612-3622.

Margiotta JF, Berg DK, Dionne VE (1987b) Cyclic AMP regulates the proportion of functional acetylcholine receptors on chicken ciliary ganglion neurons. Proc Natl Acad Sci USA 84:8155-8159. 
Marshall LM (1985) Presynaptic control of synaptic channel kinetics in sympathetic neurones. Nature 7:3612-3622.

Martin AR, Pilar G (1963a) Dual mode of synaptic transmission in the avian ciliary ganglion. J Physiol (Lond) 168:443-463.

Martin AR, Pilar G (1963b) Transmission through the ciliary ganglion of the chick. J Physiol (Lond) 168:464-475.

Matter JM, Matter-Sadzinski L, Ballivet M (1990) Expression of neuronal nicotinic acetylcholine receptor genes in the developing chick visual system. EMBO J 9:1021-1026.

McEachern AE, Jacob MH, Berg DK (1989) Differential effects of nerve transection on the ACh and GABA receptors of chick ciliary ganglion neurons. J Neurosci 9:3899-3907.

Meriney SD, Pilar G (1987) Cholinergic innervation of the smooth muscle cells in the choroid coat of the chick eye and its development. J Neurosci 7:3827-3839.

Moss BL, Role LW (1993) Enhanced ACh sensitivity is accompanied by changes in ACh receptor channel properties and segregation of ACh receptor subtypes on sympathetic neurons during innervation in vivo. J Neurosci 13:13-28.

Moss BL, Schuetze SM, Role LW (1989) Functional properties and developmental regulation of nicotinic acetylcholine receptors on embryonic chicken sympathetic neurons. Neuron 3:597-607.

Narayanan $\mathrm{CH}$, Narayanan $\mathrm{Y}$ (1976) An experimental inquiry into the central source of preganglionic fibers to the chick ciliary ganglion. J Comp Neurol 166:101-109.

Pilar G, Nunez R, McLennan IS, Meriney SD (1987) Muscarinic and nicotinic synaptic activation of the developing chicken iris. J Neurosci 7:3813-3826.

Role LW (1988) Neural regulation of acctylcholinc scnsitivity in embryonic sympathetic neurons. Proc Natl Acad Sci USA 85:28252829.

Salpeter MM (1987) Development and neural control of the neuromuscular junction and of the junctional acetylcholine receptor. In: The vertebrate neuromuscular junction (Salpeter MM, ed), pp 55115. New York: Liss.

Schoenfeld TA, McKerracher L, Obar R, Vallee RB (1989) MAP IA and MAP 1B are structurally relatcd microtubulc associatcd protcins with distinct developmental patterns in the CNS. J Neurosci 9:17121730.

Schoepfer R, Halvorsen SW, Conroy WG, Whiting P, Lindstrom J (1989) Antisera against an acetylcholine receptor $\alpha 3$ fusion protein bind to ganglionic but not to brain nicotinic acetylcholine receptors. FEBS Lett 257:393-399.

Schuetze SM, Role LW (1987) Developmental regulation of nicotinic acetylcholine receptors. Annu Rev Neurosci 10:403-457.

Sims KB, Cranđall JE, Kosik KS, Williams RS (1988) Microtubuleassociated protein 2 (MAP 2) immunoreactivity in human fetal neocortex. Brain Res 449:192-200.

Smith MA, Stollberg J, Lindstrom JM, Berg DK (1985) Characterization of a component in chick ciliary ganglia that crossreacts with monoclonal antibodies to muscle and electric organ acetylcholine receptor. J Neurosci 5:2726-2731.

Smith MA, Margiotta JF, Franco A Jr, Lindstrom JM, Berg DK (1986) Cholinergic modulation of an acetylcholine receptor-like antigen on the surface of chick ciliary ganglion neurons in cell culture. J Neurosci 6:946-953.

Sternberger LA (1979) Immunocytochemistry, p 93. New York: Wiley.

Stollberg J, Berg DK (1987) Neuronal acetylcholine receptors: fate of surface and internal pools in cell culture. J Neurosci 7:1809-1815.

Tuttle JB (1983) Interaction with membrane remnants of target myotubes maintains transmitter sensitivity of cultured neurons. Science 220:977-979.

Tzartos SJ, Rand DE, Einarson BL, Lindstrom JM (1981) Mapping of surface structures of Electrophorus acetylcholine receptor using monoclonal antibodies. J Biol Chem 256:8635-8645.

Vijayaraghavan S, Schmid HA, Halvorsen SW, Berg DK (1990) Cyclic AMP-dependent phosphorylation of a neuronal acetylcholine receptor $\alpha$-type subunit. J Neurosci 10:3255-3262.

Witzemann V, Brenner HR, Sakmann B (1991) Neural factors regulate AChR subunit mRNAs at rat neuromuscular synapses. J Cell Biol $114: 125-141$ 